\title{
Манипулятивный потенциал метаязыковых операторов в российском политическом дискурсе
}

\section{Manipulative Potential of Metalanguage Operators in Russian Political Discourse}

\author{
Екатерина Рычева
}

(Прага, Чехия)

\begin{abstract}
:
In the contemporary Russian political discourse, various types of metalanguage operators are used, which increase the expressiveness and emotionality of a politician's speech, enhancing the pragmatic effect on the audience. The author investigates the manipulative potential of metalanguage operators in contemporary Russian political discourse. The research material was collected from transcripts of public speeches of leading Russian politicians-V. Putin and D. Medvedev. The author comes to the conclusion, that the main methods of intensifying the manipulative potential by using metalanguage operators in the political discourse are: 1) appeal to the recipient's experience; 2) an indication of the level of education and professional competence of the politician; 3) an indication of the sincerity and honesty of the politician; 4) mitigation of speech aggression; 5) expression of subjective assessment. The study showed that politicians often use metalanguage operators to comment and interpret proverbs and sayings, borrowed words and expressions, new and obsolete words, as well as jargon, argo and rude words.
\end{abstract}

\section{Key words:}

political discourse; metalanguage operators; manipulative potential; pragmatic effect; expression 
В настоящее время для политических выступлений в публичном пространстве (встречи с избирателями, интервью, трансляции, блоги политиков в социальных сетях и т.д.) важен не только сам факт трансляции говорящим какой-либо информации, но и способ ее преподнесения. Политики находятся в постоянном поиске языковых и метаязыковых средств, которые бы помогли им максимально эффективно воздействовать на сознание реципиента. С этой целью в политическом дискурсе широко используются различные метаязыковые операторы, которые призваны интенсифицировать прагматический потенциал высказывания.

Говоря о данном типе комментирования, лингвисты используют ряд терминов, таких как метатекст [BACHTIN 1979; VEŽBICKA 1978], метаоператор [VEŽBICKA 1999], рефлексив [VEPREVA 2005; ŠEJGAL 2002], метаязыковые высказывания [BULYGINA, ŠMELEV 1999], контекст-мнение [LUK'JANOVA 1986] и др. В данной работе будет использоваться термин метаязыковой оператор, под которым мы будем понимать особый тип комментария, который сопровождает актуальную для говорящего часть высказывания, эксплицитно или имплицитно транслируя оценку и отношение адресанта к факту действительности. По отношению к комментируемой части высказывания метаязыковые операторы могут находиться в любой позиции (препозиция, интерпозиция или постпозиция).

Метакоммуникация неразрывно связана с сущностью языка политики как инструмента убеждения и пропаганды определенных идей и удержания власти. По мнению Е.Л. Макаровой, сам термин метакоммуникация связан с уровнем передачи субъективных отношений и оценок коммуникантов к передаваемой информации, способу ее изложения и особенностям процесса ее восприятия [MAKAROVA 1994, 10]. Таким образом, первичной задачей метаязыковых комментариев является воздействие на реципиента, которое может осуществляться как эксплицитно, так и имплицитно.

Метаязыковые операторы организуют процесс коммуникации, моделируют речевое поведение собеседников, помогают пониманию авторской интенции, обеспечивают более эффективное восприятие текста реципиентом. По словам И. Т. Вепревой, «говорящий, включая рефлексив в свое дискурсивное пространство, ориентируется на слушающего, учитывая потенциальные возможности адресата понять смысл сказанного» [VEPREVA 2005, 102]. Комментируя и интерпретируя различные факты или суждения, политик старается опираться на опыт аудитории, ее возраст, социальное положение, уровень образования и т. д., что позволяет ему избежать коммуникативной неудачи. Следовательно, на основе анализа метаязыковых операторов можно реконструировать речевой портрет реципиента, так как корпус метаязыковых высказываний позволяет 
воссоздать предполагаемый «лингвоментальный «автопортрет» россиян» [CHLEBDA 1999, 64]. В политическом дискурсе речь политика всегда обращена к аудитории, поэтому использование тех или иных языковых и метаязыковых средств обусловлено пресуппозициями адресата.

Метаязыковые операторы выполняют в речи политиков различные функции. Говоря о существовании двух функциональных типов языковой рефлексии, И.Т. Вепрева выделяет «1) рефлексивы, реагирующие на коммуникативное напряжение и осуществляющие контроль на речепорождающем уровне; 2) рефлексивы, реагирующие на концептуальное напряжение в речемыслительной деятельности и возникающие на уровне превербального этапа формирования речевого высказывания» [VEPREVA 2005, 103]. Исследователь предлагает рассматривать метаречевые высказывания (поверхностный уровень) и метаконцептуальные, метатезаурусные (глубинный уровень). Таким образом, при анализе функциональных типов рефлексивов следует учитывать специфику обращения к когнитивному опыту участников процесса коммуникации.

Обращаясь к сфере политического дискурса, Е. И. Шейгал разграничивает «акты интерпретации фактов речи и акты интерпретации денотата, стоящего за фактами речи» [ŠEJGAL 2002]. Лингвист отмечает, что в рефлексивах первого типа, связанных с оценкой, интерпретация фактов речи может представлять собой толкование сигнификативного содержания фактов речи или интерпретацию их коннотативного аспекта. Второй тип рефлексивов представляет собой интерпретацию высказывания с точки зрения стоящего за ним денотата, а именно - градуальную коррекцию в сторону возрастания или снижения, а также обнаружение второго плана сообщения [ŠEJGAL 2002].

Целью настоящей статьи является выявление манипулятивного потенциала метаязыковых операторов в современном российском политическом дискурсе. Материал исследования собран методом сплошной выборки из стенограмм публичных выступлений ведущих российских политиков В. Путина и Д. Медведева (с 2012 по 2020 гг.) [Pravitelstvo... 2020; Prezident... 2020]. Мы рассматриваем метаязыковые операторы как одно из средств оказания манипулятивного воздействия на реципиента сообщения в политическом дискурсе, понимая под манипуляцией «намеренное скрытое применение говорящим особых языковых средств с целью воздействия на сознание адресата, навязывания ему определенного представления о действительности, отношения к объекту коммуникации, оценки, а также для побуждения адресата к определенным действиям в интересах говорящего» [RYČEVA, SOROKA 2019, $71]$.

По нашему мнению, основными приемами использования метаязыковых операторов в политическом дискурсе, при помощи которых осуществляется 
желаемое манипулятивное воздействие на адресанта, являются: 1) обращение к опыту реципиента; 2) указание на уровень образования и профессиональной компетенции политика; 3) указание на искренность и честность политика; 4) смягчение речевой агрессии; 5) выражение субъективной оценки.

\section{1. Обращение к опыту реципиента}

Под опытом реципиента подразумевается специфический объем знаний, который может быть как социальным, который определяет принадлежность индивида к конкретной культуре, народу, религии (обычаи, ценности, традиции, социальные роли, язык), так и личным (совокупность знаний, навыков, умений отдельного индивида). При апелляции к такому типу когнитивных структур адресант стремится максимально приблизиться к реальности адресата, автоматически создавая уровень так называемого «дискурсивного комфорта» [LUTOVINOVA 2009; GORINA 2015].

Используя метаязыковые операторы типа как вы видели, как вы знаете, как вы помните, политики намеренно представляют информацию как общеизвестный факт, истинность которого не подвергается сомнению: «Mbl, как вы видели, вводим рейтинги и не только в стране в иелом отслеживаем деловой климат, но и в регионах Российской Федерации постоянно на это обращаем внимание, нацеливаем региональные команды на эту работу, и в целом, так, скромно скажу, кое-что получается», "Давайте к этому вернёмся ещё. Но Вы знаете наверняка, поскольку Bы этим занимались, что у юристов есть определённые опасения в связи с этой возможной процедурой предъявления исков к неопределённому кругу лищ», «Когда майские указы, если Вы вспомните, только вышли, сразу начался «плач Ярославны» по поводу того, что они неисполнимы и что это слишком большая нагрузка на бюджеты всех уровней, что это потащит развитие экономики вниз, что нельзя так планировать повышение заработных плат, что это неприемлемо, заработных плат в бюджетной сфере прежде всего», «Вы же знаете, мы регулярно, два раза в год, в Сочи собираемся. Кроме текущей работы, которой я тоже постоянно занимаюсь, я что то «в разы» не помню». Использование данных метаязыковых операторов не только фокусирует внимание реципиента на проблемах, о которых идет речь, но и усиливает выразительность высказывания.

Стоит обратить внимание на употребление В. Путиным конструкций типа как говорят, как у нас в народе говорят, что называется, которые часто предшествуют или следуют за употреблением фразеологической единицы: «Что касается повышения ответственности, то у нас с этим, как в народе говорят, «не заржавеет», «Нашей стране пришлось пройти через многие испытания, 
и всегда разведчики были, что называется, «на передовой», «Предлагаю, уважаемые коллеги, ещее раз собраться этой осенью и, что называется, «сверить часы», посмотреть, как реализуются намеченные планы и ещё раз поговорить о том, как складььватся ситуащия в отрасли». Таким образом говорящий подчеркивает не только свою образованность, но и принадлежность к определенной социальной группе - к носителям русской лингвокультуры.

В некоторых случаях политик дает собственную интерпретацию значения фразеологической единицы, предлагая аудитории «готовый» вариант толкования: «У нас, вы знаете, в народе часто говорят «врач от бога». Такая оценка свидетельство высокого уровня знаний, профессионализма, компетентности доктора, его заботливого, участливого отношения к пациенту». При помощи данного приёма говорящий стремится к максимальному достижению коммуникативной и прагматической цели, предупреждая возможную неверную трактовку семантики устойчивого оборота.

Политики, употребляя в своей речи просторечную и жаргонную лексику, также сопровождают её метаоператорами как говорят, как у нас в народе говорят. По словам В. Т. Вепревой, данные метаоператоры указывают на то, что говорящий «прячется» за чужую речь, ссылается на общее мнение, как бы снимает с себя ответственность за сказанное [VEPREVA 2014]. Следовательно, при помощи метаязыковых операторов данного типа политик делает возможным использование стилистически сниженной лексики для придания речи большей выразительности.

Следует отметить, что подобные метаоператоры служат сильным прагматическим средством, указывая на принадлежность политика к определенной культуре и на специфическую модель мышления и поведения: «Понять можно: подешевле, или, как у нас в народе ещё говорят... Но не буду сленгами здесь разбрасыьваться, но, в общем, понятно, о чём идёт речь. Но всё хорошо в меру», «Это могут быть хакеры, кстати сказать, в Соединённых Штатах, которые очень ловко и профессионально перевели, как у нас говорят, «стрелку» на Россию», «Есть ведь такие люди, которые токуют сами по себе, им что ни говоришь - как фон такой - ж-ж-ж... Вроде как сказал, а он или она и не слушают совсем, как у нас в народе говорят, лепят горбатого, и всё». Говорящий способен переключаться с одного субъязыка на другой в зависимости от ситуации общения и предмета коммуникации, прибегая к использованию сниженной лексики и фразеологии для достижения максимального прагматического эффекта.

В процессе коммуникации политик всегда стремится установить контакт с аудиторией, завладеть ее вниманием и получить от нее одобрение своих слов. Для этого он может апеллировать к коллективному культурному опыту электората, употребляя такие выражения с лексемой известный как известная 
поговорка, известная шутка, как известно: «Но вы знаете, у нас есть известная шутка: те, кто не хочет кормить свою армию, будут кормить чужую. Это совсем старая», «Bы знаете известную поговорку, у нас в народе говорят: сделал дело - гуляй смело», «Конечно, благими намерениями, как известно, вымощена дорога в ад, так у нас говорят, и ветеринарные службы наверняка оббясняют такое своё рвение защитой интересов потребителя». Политик подчеркивает общеизвестность употребляемых выражений, добиваясь подсознательного одобрения своих слов аудиторией.

\section{2. Указание на уровень образования и профессиональной компетенции политика}

Метаязыковые комментарии насколько мне известно, как правило демонстрируют осведомленность политика, обладание определенной информацией, которой он желает поделиться с аудиторией: «Школа, насколько мне известно, мне уже Дмитрий Юрьевич Миронов рассказывал об этом, она была создана и функционирует ешё с тысяча восемьсот какого-то лохматого года, то есть это конеи XIX века», «На самом деле история России показывает, что мы, как правило, и жили под санкциями, начиная с того момента, когда Россия начала вставать на ноги и чувствовать себя крепко», «Сегодняшняя жизнь требует, как правило, узкой специализации, а для этого нужно как следует подумать и вникнуть в ткань той проблемы, которую вы хотите сделать для себя самой важной и самой главной». При помощи данных метаязыковых операторов говорящий подчеркивает свою профессиональную компетентность, что повышает авторитетность его суждений для реципиента.

Политики употребляют метаоператоры в целом, в конце концов, по сути, как показывает практика, это значит, указывающие на способность анализировать происходящее и давать взвешенную оценку: «Должен сказать, что есть какие-то недовыполнения, но в целом, как бы высоко ни были подняты планки этих указов, если бы их не было, то не было бы и результатов, которые мы имеем сегодня», «Как показывает практика, ни одно государство, каким бы сильным оно ни было, не может в одиночку справиться с этим злом, не в состоянии надёжно защитить и своих граждан», «Они могут и побольше получать за вредность, ещё за что-то, но нам нужно определить приоритеть и нужно, чтобы общество осознало это, в конце концов, к этому пришло постепенно. Это делается постепенно. Сразу, одним рывком, не сделаешь», «Что в этой связи можно сказать? Конечно, всё должно быть в рамках разумного. Водоохранная зона, о которой Bb, по сути, сейчас говорите, она должна соответствовать не только статусу и значению Байкала. Она должна соответствовать и потребностям 
людей, которые там же живут». С помощью данных метаязыковых операторов говорящий разъясняет и трактует факты действительности, представляя итог своих рассуждений как единственно верный вариант.

Показателем эрудированности и образованности политика выступают метаоператоры, комментирующие и интерпретирующие крылатые выражения. Политики активно используют в речи широкоизвестные выражения из разных источников (литература, мемуары и высказывания известных людей), сопровождая их своими комментариями и толкованиями: «Вы знаете, эта «детская болезнь левизны в коммунизме», как классик писал в своё время, у нас тоже прошла», «Я говорил и хочу ещё раз повторить, перефразировать великого Ломоносова, когда он говорил, что богатство России будет прирастать Сибирью. Теперь богатство России должно прирастать Арктикой», «Так что в целом, конечно, ничего хорочего нет, но сказать, что это смертельно, пожалуй, это, как здесь Канцлер Австрии говорил, припоминая Марка Твена. «Слухи о моей смерти, - как он однажды написал, - сильно преувеличены». Так вот и по поводу санкций можно сказать. Но лучще, конечно, чтобы этого не было, и нужно с этим заканчивать», «Вы знаете, по большому счёту лучше не уповать на каких то сказочных персонажей. Помните, в советское время была песенка такая: «Никто нам не поможет - ни бог, ни царь и ни герой». Всё своей собственной рукой мы должны сделать. Поэтому, если мы будем ждать чудес от золотой рыбки, то мы можем оказаться, как в сказке Пушкина, у разбитого корыта в конце концов», «Это некая пассионарность, о которой Гумилёв говорил в своё время, которая толкает нашу страну вперёд». Следует отметить, что использование крылатых выражений зависит от целевой аудитории, к которой обращается политик. Метаязыковые операторы, комментирующие крылатые выражения, помогают политику гармонизировать процесс коммуникации и избежать коммуникативной неудачи.

\section{3. Указание на искренность и честность политика}

Политики прибегают к использованию метаоператоров честно говоря, честно сказать, чтобы смоделировать в глазах аудитории образ бескорыстного, искреннего и честного человека, обладающего правдой, истинным знанием: «У меня тяжёльй рабочий день заканчивается так поздно, что мне уже не до Instagram: я думаю, как бы мне быстрее до койки добраться, до постели. (Смех.) Поэтому если честно, то сотрудники моего аппарата, Администрации, конечно, очень активно используют интернет во всех его ипостасях, но я лично практически этим не пользуюсь», «Мы это создали, это делается на общественных началах, но мне, честно говоря, не приходило в голову то, что Вы сейчас сказали», «Честное 
слово, просто перестал. Но преподаватели были такие умные, надо отдать им должное, я их с благодарностью вспоминаю, они увидели, что я перестал заниматься», «Честно говоря, мне даже в голову это не приходило, но спасибо, что Вы сказали», «Нужно ли на первый план выцвигать вопросы, которые Вы сейчас затронули, честно говоря, не знаю - как бы это не повлияло», «Странно, согласитесь, честное слово, это как-то за скобками здравого смысла». Говорящий намеренно использует данный тип метаоператоров, направляя слушающего по желаемой траектории рассуждения, убеждая его в истинности предоставляемой информации.

С помощью метаязыкового оператора что же греха таить политик показывает, что он осведомлен о негативном ходе вещей, но при этом он максимально честен перед аудиторией и способен нести за это ответственность. Имеется в виду, что сообщаемое до этого открыто не обсуждалось и является, по мнению говорящего, негативным, предосудительным: «Значит, недоволен собой. Виноват, может, не надо было говорить, но что же греха таить. В России есть такой грех. Отмолим», «И мне бы очень не хотелось, чтобы эта работа - так, как это иногда бывает, что греха таить, - превращалась в чисто формальное «броуновское» движение, никому не нужное. Очень бы хотелось, наоборот, чтобы это была содержательная работа, нацеленная на улучшение качества работы министерств и ведомств». Адресант подчеркивает свою открытость по отношению к адресату, тем самым стремится установить и поддержать с ним доверительные отношения.

Желание политика говорить прямолинейно и начистоту отражает использование метаоператоров шутки шутками, без шуток: «Я серьёзно, без всяких шуток, хочу понять Ваши ощущения. Сейчас, знаете, я не шучу, по серьёзному спрашиваю, внутренние ощущения - Bь уверены, надёга есть внутренняя?», «Но наши партнёры должны понимать, что шутки шутками и их работа по продвижению информационных продуктов, направленных против России, это одно, а серьёзные вопросы, особенно в области ядерных вооружений, - это совершенно другое, и нужно быть в состоянии исполнить свои обязательства». В данных высказываниях говорящий акцентирует внимание реципиента на серьезности намерений, рассудительности своих слов и действий, о желании обстоятельно решить существующую проблему.

\section{4. Смягчение речевой агрессии}

Современные политики в публичных выступлениях иногда прибегают к использованию сленга, арго и просторечной лексики для придания речи большей экспрессивности и эмоциональности. Намеренное снижение стили- 
стического регистра свидетельствует о проявлении речевой агрессии, которую можно определить как «целенаправленное коммуникативное действие, ориентированное на то, чтобы вызвать негативное эмоционально-психологическое состояние у субъекта речевого воздействия» [SEDOV 2005, 33]. Целью подобных высказываний политиков является не только демонстрация сиюминутной негативной реакции, но и провокация общественного резонанса, создание информационного повода, позволяющего как можно дольше обсуждать речь политика в средствах массовой информации и бытовом общении.

В политическом дискурсе функционируют специфические конструкции если можно так сказать, надо прямо сказать, прямо скажем, которые, с одной стороны, подчеркивают прямолинейность и открытость говорящего по отношению к слушающему, а с другой - выполняют этикетную функцию, которая помогает частично смягчить негативную коннотацию используемых со сниженной стилистической окраской, а также установить контакт между участниками коммуникации, повышая уровень доверия между ними: «Если так можно сказать, сегодня карты сдаются по новой: будут формироваться принципиально новые рынки товаров и услуг, появляться новые лидеры», «В такой ситуации с конкурентами, в том числе в глобальной бизнес-среде, конечно, надо прямо сказать, церемониться не будут. В ход могут пойти любые формы давления, любые формы конкурентной борьбы», «Техника в Российской армии устаревала, сами Вооружённые Силь находились, прямо скажем, в плачевном состоянии».

Использование метаязыковых операторов данного типа указывает на то, что политики намеренно включают в высказывание сниженную и грубую лексику. Таким образом, говорящий признает за собой проявление девиантного речевого поведения, недопустимого в сфере публичной коммуникации: «Надо говорить, надо говорить и не стесняться. И не для того, чтобы, прошу прощения за моветон, не под камеры будет сказано, жабры раздувать, какие мы великие, нет». Таким образом, этикетная функция метаязыковых операторов выражается в установлении и поддержании контакта с аудиторией через демонстрацию уважительного отношения к ней при помощи особых речевых формул.

К этикетным метаязыковым операторам можно отнести выражения с компонентом «Бог» слава богу, дай бог памяти, не дай бог и т. д., представляющие собой десемантизированные (полностью или частично) речевые конструкции, указывающие на отношение говорящего к называемому предмету или явлению: «Мы предали эту информацию гласности. Слава богу, у тех, кто планировал эту акцию, вовремя хватило ума этого не делать», «Наша полиция, слава богу, пока, во всяком случае, не применяет ни дубинки, ни слезоточивый газ, 
ни другие крайние меры наведения порядка, что мы часто видим в других странах, в том числе и в Соединённых Штатах», «Была принята программа о расселении временного жилья в районе БАМа, и мы переселили, дай бог памяти, девять тысяч семей, а посчитали, что это примерно девять тысяч». Данные метаязыковые операторы выступают в качестве акцентов, которые указывают на ключевые, по мнению говорящего, смысловые части высказывания.

\section{5. Выражение субъективной оценки}

Метаязыковые операторы данного типа отражают разноаспектную субъективную оценку политиком какого-либо предмета или явления действительности, а также индивидуальную интерпретацию коммуникативного замысла. Основной целью говорящего является эксплицитное заявление о своей политической позиции, предпочтениях и точке зрения. Метаязыковые комментарии с выражением субъективной оценки часто сочетаются с другими средствами выразительности, что ведет к интенсификации эмоциональной и экспрессивной окраски высказываний. Например, в речи В. Путина часто встречается прием нанизывания слов и выражений с определенной коннотацией: «Да ни о чём не говорили, просто общие слова, просто общие слова о том, что нам нужно подумать о том, как нам выстраивать отношения. А что, не нужно думать о том, как выстрачвать отночения? Всё с кондачка делать, вообще бездумно, что ли? Ничего конкретного, просто ноль, зеро, вообще ничего. Удивительно просто». В данном высказывании, кроме нанизывания оценочных метаоператоров, говорящий употребляет фразеологическую единицу с кондачка с негативной коннотацией со значением «делать что-либо легкомысленно, несерьёзно; не думая или совсем не понимая дела» [FJODOROV 2008], а также несколько риторических вопросов, что усиливает прагматический эффект данного высказывания.

С помощью метаоператоров чушь какая-то, бред какой-то, ерунда какая-то политик комментирует то, что вызывает у него негативное отношение. Приведенные метаоператоры, комментирующие содержательную сторону речи, позволяют аудитории фиксировать оценку явления (правильно/неправильно, хорошо/плохо): «Мы же для того предусмотрели и 10 тысяч, 50, 100 тысяч, чтобь помочь людям, а не брать с них эти деньги назад. Это какой-то бред просто. Мы обязательно с этим разберёмся, я Вас уверяю», «Вы что думаете, со всего мира и из Соединённых Штатов посол мне каждый день докладывает, с кем он встречается, что обсуждает? Бред какой-то. Вы понимаете, что Bы спрашиваете, или нет?», «Вы знаете, я видел то, что происходило. Откровенно сказать, для меня это было тоже большим удивлением. 
Ну такой бред несут, понимаете! Непонятно вообще, откуда взялись эти люди, которые распространяют такую информацию. Просто какая-то катастрофа!». При помощи использования оценочных слов и выражений и риторических фигур (восклицания, вопросы и обращения) политик транслирует аудитории резко негативное отношение к предмету речи, убеждая реципиента в своей правоте.

Политики высказывают субъективное мнение при помощи метаязыковых комментариев безусловно, конечно, очевидно, выражающих уверенность в правдивости сведений, о которых идет речь: «Но нам бы хотелось восстановить кооперацию в целом, там ещё не всё потеряно. Это пошло бы, безусловно, на пользу как украинской экономике, так и российской», «Не с целью провокации, а с иелью добиться изменения к лучшему. Это, конечно, тонкая грань, но здесь люди, которье понимают эту грань, чувствуют её», «Сказать, что там наступил какой то коренной перелом, всё таки об этом говорить рано, но то, что мы выполнили свою задачу, - это очевидно». Данные метаязыковые операторы указывают на рациональную реакцию говорящего по отношению к предмету речи, помогая политику убедить аудиторию в правдивости его слов.

Подавляющее большинство проанализированных высказываний российских политиков представлено репрезентативами, что обусловлено нарративностью изложения и желанием говорящего проинформировать аудиторию о своей политической позиции - разного рода сообщения, утверждения, констатации, интерпретации, прогнозы и т. д. Для усиления убеждающего эффекта используются сочетание речевых актов (репрезентатив + экспресив или репрезентатив + директив) в пределах смысловой синтагмы: говорящий транслирует свою позицию по поводу проблемной ситуации, затем при помощи метаязыкового оператора демонстрирует субъективное отношение к предмету или явлению.

Метаязыковые операторы в речи политиков способствуют реализации контекстуального дейксиса, обеспечивая адекватную интерпретацию информации и ее максимального понимания аудиторией («Если так можно сказать, сегодня карты сдаются по новой: будут формироваться принципиально новые рынки товаров и услуг, появляться новые лидеры», «Предлагаю, уважаемые коллеги, ещё раз собраться этой осенью и, что называется, «сверить часы», посмотреть, как реализуются намеченные планы и ещё раз поговорить о том, как складывается ситуация в отрасли»). Дейктические элементы такого типа связаны с конкретным контекстом семантическими и синтаксическими связями, обеспечивая желаемую трактовку реципиентом конкретного коммуникативного сообщения.

Кроме того, метаязыковые операторы участвуют в формировании дискурсивного дейксиса, помогая политику выразить отношение к ситуации, о которой идёт речь («Bы же знаете», «если Bы вспомните»). При помощи конструкций 
такого типа политик стремится определенным образом воздействовать на адресата сообщения, моделируя процесс восприятия и осмысления сказанного.

Речь политиков насыщена различными единицами личностного дейксиса. Так, благодаря использованию местоимения «мы» говорящий идентифицирует себя с народом и государством, подчеркивая свою причастность к общественным делам страны, интересы которой он представляет («нам бы хотелось»; «как у нас в народе говорят»). При помощи местоимения «я» политик указывает на субъективную оценку и отношение к какой-либо проблеме, акцентируя внимание реципиента на глубоких переживаниях говорящего ( $У$ меня тяжёльй рабочий день заканчивается так поздно, что мне уже не до Instagram», «для меня это было тоже большим удивлением»). В некоторых случая выбор местоимения «я» показывает желание политика представить себя в качестве эксперта в определенной области («A я что говорил? Я говорил о том, что недопустимо, когда одна страна, Соединённые Штаты, распространяет свою юрисдикцию за рамки своих национальных границ»; «насколько мне известно»). Местоимение «вы» позволяет политику реализовать различные эмотивные смыслы и прагматические установки по отношению к реципиенту - убеждение, увещевание и т. п. («насколько Вы знаете наверняка», «если Вы вспомните»). Напротив, при помощи местоимения «они» политик обозначает дистанцию между говорящим и референтом, противопоставляя их в определенном контексте (Поэтому они всегда были против и сейчас вот. И против «Северного потока - 1» они же боролись, теперь так же борются против «Северного потока - 2»).

Итак, в политическом дискурсе используются различные типы метаязыковых операторов, которые повышают выразительность и эмоциональность речи политика, усиливают прагматический эффект на аудиторию, реализуя манипулятивный потенциал. Метаязыковые операторы в речи российских политиков способствуют формированию у аудитории имиджа определенного политика, указывая на его принадлежность к русскому народу и культуре, на особенности профессиональной принадлежности говорящего, на высокий уровень образования и эрудированности политика, его компетентность и опыт.

Как показало исследование, метаоператоры чаще всего комментируют и интерпретируют пословицы и поговорки, крылатые выражения, профессионализмы, новые и устаревшие слова, жаргонизмы, арготическую и просторечную лексику. Политики актуализируют в публичной речи целый комплекс ценностных характеристик языковых единиц, что приводит к увеличению суггестивного воздействия на реципиента. 


\section{Библиография:}

BACHTIN, M. M. (1979): Èstetika slovesnogo tvorčestva. Moskva.

BULYGINA, T. V., ŠMELEV, A. D. (1999): Čelovek o jazyke (metajazykovaja refleksija $v$ nelingvističeskich tekstach). In: Logičeskij analiz jazyka. Obraz čeloveka v kul'ture i jazyke. Moskva, s. 146-161.

FJODOROV, A. I. (2008): Frazeologičeskij slovar' russkogo literaturnogo jazyka. Moskva. GORINA, Je. V. (2015): Diskursivnaja model' interneta. Izvestija Ural'skogo federal'nogo universiteta. Serija 1. Problemy obrazovanija, nauki i kul'tury, 2015, № 2 (138), S. 22-30.

CHLEBDA, V. (1999): Šest' soobraženij po voprosu o jazykovom samosoznanii. In: Rusistika. Sankt-Peterburg, s. 62-67.

LUK'JANOVA, N. A. (1986): Ėkspressivnaja leksika razgovornogo upotreblenija: Problemy semantiki. Novosibirsk.

LUTOVINOVA, O.V. (2009): Lingvokul'turologičeskije charakteristiki virtual'nogo diskursa. Avtoreferat dissertacii na soiskanije učenoj stepeni doktora filologičeskich nauk. Volgograd.

MAKAROVA, Je. L. (1994): Obučenije sredstvam metakommunikacii v argumentirujuščem diskurse (nemeckij jazyk). Avtoreferat dissertacii na soiskanije učenoj stepeni kandidata pedagogičeskich nauk. Moskva.

Pravitel'stvo Rossii. Oficial'nyj sajt. <http://government.ru/>. [online]. [cit. 30. 4. 2020].

Prezident Rossii. <http://kremlin.ru/>. [online]. [cit. 30. 4. 2020].

RYČEVA, Je. A., SOROKA, S. S. (2019): Manipuljativnyje strategii i taktiki v reči rossijskich i češskich pravych politikov v internet-kommunikacii. In: MELIKJAN, V. Ju. (ed.): Jazyk i pravo: aktualnyje problemy vzaimodejstvija. Vypusk 9. Rostov-na-Donu, s. $71-81$.

SEDOV, K. F. (2005): Rečevaja agressija v povsednevnoj kommunikacii. In: Sbornik Rečevaja agressija v sovremennoj kul'ture. Čeljabinsk, s. 32-37.

ŠEJGAL, Je. I. (2002): Refleksivy v političeskoj kommunikacii. In: Mežvuzovskij sbornik naučnych trudov Teoretičeskaja i prikladnaja lingvistika. Aspekty metakommunikativnoj dejatelnosti. Vypusk 3. Voronež, s. 133-141.

VEPREVA, I. T. (2005): fazykovaja refleksija v postsovetskuju èpochu. Moskva.

VEŽBICKA, A. (1978): Metatekst v tekste. In: Novoje v zarubežnoj lingvistike. Vypusk 8.

Lingvistika teksta. Moskva, s. 402-421.

VEŽBICKA, A. (1999): Semantičeskije universalii i opisanije jazykov. Moskva.

\section{About the author}

Ekaterina Rycheva, Charles University, Faculty of Arts, Department of East European Studies, Prague, Czech Republic, ekaterina.rycheva@ff.cuni.cz 
